\title{
Perfluorinated sulfonic acid ion-exchange membrane doped silicotungstic acid thermal stability and conductivity
}

\author{
Yi heng Lu*, Shuang chun Ma, Ying Chen, Wen quan Feng \\ School of Chemical Engineering, \\ Anhui University of Science and Technology, Huainan, Anhui, China, \\ *E-mail: yhlu2000@163.com
}

\begin{abstract}
Keywords: Silicotungstic acid, silane coupling agents, composite membrane, thermal stability, proton conductivity
\end{abstract}

\begin{abstract}
Perfluorinated sulfonic acid ion exchange membrane doped the silicotungstic acid thermal stability and thermal degradation kinetics were studied by means of thermal gravimetric analysis in a nitrogen atmosphere, the heating rate used respectively was $5,10,20$ and $30^{\circ} \mathrm{C} / \mathrm{min}$. Using the Kissinger, Flynn-Wall-Ozawa, Friedman and Starink methods, non-isothermal kinetics data of composite membrane doped the silicotungstic acid were analyzed. TG-DTG curves showed that for proton exchange composite membranes, when decomposition rates reached 5 and $10 \%$, the lowest thermal degradation temperature respectively was 255.9 and $310.9^{\circ} \mathrm{C}$. The results calculated by various methods indicated that the average value of apparent activation energy of composite membrane was $144.5 \mathrm{~kJ} / \mathrm{mol}$. When composite film was measured at -30 and $90^{\circ} \mathrm{C}$, the conductivity of film respectively was $1.42 \times 10^{-6} \mathrm{~S} \cdot \mathrm{cm}^{-1}$ and $3.12 \times 10^{-5} \mathrm{~S} \cdot \mathrm{cm}^{-1}$.
\end{abstract}

\section{Introduction}

With high temperature resistant, low humidity and high proton conductivity problem in the field of polymer electrolyte membrane fuel cell (PEMFC) have not been solved [1]. Now there are more reported [2], such as the heteropolyacid was application for fuel cell [3], the phosphotungstic acid containing dense sulfonated block copolymers composite membrane used for fuel cell [4], research of PVDF silica gel as a support, phosphotungstic acid immobilized membrane for direct methanol fuel cells[5], based on sulfonated polyphenylene sulfone/phosphotungstic acid/silica hybrid film, preparation and evaluation properties, in low humidity conditions for proton exchange membrane fuel cell [6], preparation combined graphene and phosphotungstic acid and self humidifying composite membrane [7], based on sulfonated poly (arylene ether) supports for heteropolyacid nanocomposite membranes for proton exchange membrane fuel cells [8], studying the heteropolyacid cesium hydrogen salt / Nafion nanocomposite membrane[9], non fluorine containing PVA/PWA/GPTES/

MPTMS $/ \mathrm{P}_{2} \mathrm{O}_{5} / \mathrm{GA}$ based hybrid composite film preparation, measuring the electrochemical performance [10], characterization of the inorganic and organic nano hybrid membranes, based on the PWA-PMA-TEOS-GPTMS- ${ }_{3} \mathrm{PO}_{4}$-APTES combination for hydrogen fuel cells [11], the conductor polymer composite film contained heteropolyacids, used in the formation of artificial light composite film[12], based on phosphotungstic acid functionalized mesoporous silica nano-composite characterization used for high temperature proton exchange membrane [13].

This paper will further report the heat resistance and conductivity for silicotungstic acid modified composite proton exchange membrane, on the bases of our previous studies phosphotungstic acid effect[14], nano $\mathrm{SiO}_{2}$ [15] doped composite proton exchange membrane thermal stability and conductivity, and Fenton reagent effect[16], using TGA technology investigating thermal decomposition kinetics of modified membrane, inferring the possible thermal decomposition kinetics parameters such as activation energy, thermal decomposition mechanism, non-model thermal decomposition kinetics. Using the Friedman, Kissinger, Starink and Flynn-Wall-Ozawa methods, for determination of the electrical conductivity of the composite proton exchange membrane doped by the silicotungstic acid at different temperatures $\left(-30 \sim 90^{\circ} \mathrm{C}\right)$, this will be helpful to improve thermal 
stability and durability of the industry core components used for the fuel cell proton exchange membrane.

\section{Experimental}

Materials Proton exchange membrane (Perfluorosulfonic acid proton exchange membrane), colorless and transparent, trademark PFSA, thickness of $80 \mu \mathrm{m}$, industrial qualified products. The silicotungstic acid $\left[\mathrm{H}_{4}\left[\mathrm{Si}\left(\mathrm{W}_{3} \mathrm{O}_{10}\right)_{4}\right] \cdot \mathrm{xH}_{2} \mathrm{O}\right]$ and ferricyanide were all analytical pure grade and purchased from the Tianjin Guang Fu Institute of Fine Chemicals. The silane coupling agent (KH-570, $\gamma$-(methacryloxypropyl) trimethoxysilane) was purchased from the Nanjing Qian Jing Chemical Co., other reagents used such as hydrogen peroxide, methanol, sodium hydroxide, concentrated sulfuric acid, potassium ferrocyanide and potassium chloride all were analytical pure grade and used as received and without purification. De-ionized water was prepared from the distilled water generator.

\section{Membrane pretreatment}

The dimension of $1.0 \times 1.0 \mathrm{~cm}$ proton exchange membrane surface was cleaned, put into deionized water at $60^{\circ} \mathrm{Cconstant}$ temperature dipping for $1 \mathrm{~h}$, then treated membrane was dried in air for $24 \mathrm{~h}$. The membrane was immersed into a $1 \%$ solution of hydrogen peroxide at $60^{\circ} \mathrm{C}$, allowed to stand treated 1h. The resulting film was placed in $\mathrm{NaOH}$ solution $0.5 \mathrm{~mol} / \mathrm{L}$ at $80^{\circ} \mathrm{Cconstant}$ temperature water bath $1 \mathrm{~h}$, washed with deionized water, the membrane $80^{\circ} \mathrm{Cthermostatic}$ drying $12 \mathrm{~h}$.

Preparation of the silicotungstic acid doped composite membrane [14]

The proton exchange membrane size $1.0 \times 1.0 \mathrm{~cm}$ in methanol: water $=3: 1$ (volume ratio) was soaked in 1 hour, swelling of the membrane surface, as a precursor providing clearance to enter. Remove the film after swelling, placed $0.1 \mathrm{~g}$ of silicotungstic acid and $5 \mathrm{~mL} \mathrm{KH}-570$ were heated to $80^{\circ} \mathrm{Cand}$ immersed $3 \mathrm{~h}$, removed and dried at $60^{\circ} \mathrm{C}$ constant temperature $24 \mathrm{~h}$. The resulting composite membrane was placed $\mathrm{H}_{2} \mathrm{SO}_{4}$ solution $0.5 \mathrm{~mol} / \mathrm{L}$ was allowed to stand for $1 \mathrm{~h}$, the film protonated, removed and dried in vacuum to constant weight, for use.

\section{Electrolyte preparation}

Weigh potassium ferrocyanide $\left[\mathrm{K}_{4} \mathrm{Fe}(\mathrm{CN})_{6}\right] 1.0 \mathrm{mmol}$, ferricyanide $\left[\mathrm{K}_{3} \mathrm{Fe}(\mathrm{CN})_{6}\right] 1.6 \mathrm{mmol}$ and potassium chloride $25.0 \mathrm{mmol}$, deionized water, respectively dissolving, mixing, set the volume to $250 \mathrm{~mL}$, with mixed electrolyte.

Original and composite membranes were placed in the solution soak for $2 \mathrm{~min}$, with a three-electrode electrochemical impedance analyzer system to test, set the disturbance voltage was $10 \mathrm{mV}$, impedance frequency $1.0 \sim 1.0 \times 10^{6} \mathrm{~Hz}$, the reference electrode was saturated calomel electrode, an auxiliary electrode was a platinum wire electrode, the working electrode was glassy carbon electrodes. The system was placed in a water bath, the impedance were respectively measured at 20 , $30,40,50,60,70,80$ and $90^{\circ} \mathrm{C}$.

\section{Low temperature conductivity- electrolyte preparation}

Weigh potassium ferrocyanide $10 \mathrm{mmol}$, ferricyanide $16.0 \mathrm{mmol}$ and potassium chloride $0.25 \mathrm{~mol}$, respectively were dissolved in deionized water, mixed, set the volume to $200 \mathrm{~mL}$, obtaining mixed electrolyte. Measurement principle same as above, the system was placed in $-35^{\circ} \mathrm{Cmethanol}$ bath, the impedance were respectively measured at $-30,-25,-20,-15,-10,-5$ and $0^{\circ} \mathrm{C}$.

Analytical methods Electrochemical impedance analyzer used model CHI660D was provided by the Shanghai Chen Hua Instrument Co., impedance frequency range of $1.0 \sim 5.0 \times 10^{6} \mathrm{~Hz}$, the disturbance voltage of 5mv. TG-DTG curves were recorded in the SDT 2960 thermal gravimetric meter (TA Company in USA), sample film was doped with silicotungstic acid. Determination of the non-isothermal heat weightlessness was carried out, using alumina as a reference material, the carrier gas was nitrogen, flow rate of $70 \mathrm{ml} / \mathrm{min}$, heating rates of $5,10,20$ and $30^{\circ} \mathrm{C} / \mathrm{min}$, temperature range of $25-700^{\circ} \mathrm{C}$, the quality of the sample was $5.0 \sim 10.0 \mathrm{mg}$. 


\section{Theoretical background}

Silicotungstic acid doped perfluorinated sulfonic acid ion membrane was a polymer electrolyte, the thermal degradation process can be used by the non-model method and multiple scanning method to solve the kinetic parameters of the apparent activation energy E, pre-exponential factor A, linear coefficient r, commonly used methods are Flynn-Wall-Ozawa method (referred FWO method) [17] (Formula 1), Friedman method [18] (Formula 2), Starink method [19] (Formula 3), Achar-Brindley -Sharp method [20] (Formula 4) (referred ABS method) and Coats-Redfern method [21] (Formula 5) (referred CR method). In addition, use the $Z(\alpha)-\alpha$ relation can infer the most probable mechanism function $f(\alpha)$ and $G(\alpha)$ of composite film thermal degradation.

$$
\begin{aligned}
& \lg \beta=\lg [\mathrm{AE} / \operatorname{Rg}(\alpha)]-2.315-0.4567 \mathrm{E} / \mathrm{RT} \\
& \ln [\mathrm{d} \alpha / \mathrm{dt}]=\ln [\mathrm{A} \mathrm{f}(\alpha)]-\mathrm{E} / \mathrm{RT} \\
& \ln \left[\beta / \mathrm{T}^{\mathbf{1 . 8}}\right]=\mathrm{Cs}-\mathrm{E} / \mathrm{RT} \\
& \ln [\mathrm{d} \alpha / \mathrm{f}(\alpha) \mathrm{dT}]=\ln (\mathrm{A} / \beta)-\mathrm{E} / \mathrm{RT} \\
& \ln \left[\mathrm{G}(\alpha) / \mathrm{T}^{2}\right]=\ln [\mathrm{AR} / \beta \mathrm{E}]-\mathrm{E} / \mathrm{RT}
\end{aligned}
$$

Wherein, $\mathrm{d} \alpha / \mathrm{dT}$ is the decomposition rate $(\% / \mathrm{min}), \mathrm{A}$ is the pre-exponential factor $\left(\mathrm{min}^{-1}\right), \beta$ is the heating rate $\mathrm{dT} / \mathrm{dt}\left({ }^{\circ} \mathrm{C} / \mathrm{min}\right)$, the conversion rate $\alpha(\%), \mathrm{E}$ is the activation energy $(\mathrm{kJ} / \mathrm{mol}), \mathrm{R}$ is the gas constant $8.314 \mathrm{~J} / \mathrm{mol} \cdot \mathrm{K}$ and $\mathrm{T}$ is the absolute temperature $(\mathrm{K})$. When $\alpha$ constant, Cs is a constant, $G(\alpha)$ and $f(\alpha)$ were the integral mechanism functions and differential mechanism functions. Use the $Z$ $(\alpha)-\alpha$ method to infer the most probable mechanism function, substituting $\alpha$ into the $f(\alpha)$ and $G(\alpha)$, then obtained data substituting into the Equation 6. Plotting curves of $Z(\alpha)-\alpha$, it is a standard curve. Substituting experimental data $\beta, \alpha, \mathrm{T}, \mathrm{d} \alpha / \mathrm{dt}$ and the activation energy E obtained by FWO method, into the relationship (formula 7):

$$
\begin{aligned}
& \mathrm{Z}(\alpha)=\mathrm{f}(\alpha) \mathrm{G}(\alpha) \\
& \mathrm{Z}(\alpha)=\left[\mathrm{RT}^{2} / \beta \mathrm{E}\right] /(\mathrm{d} \alpha / \mathrm{dt})
\end{aligned}
$$

If the experimental curve obtained overlap with the standard curve, or all of the experimental data points fall on a standard curve, it is determined that the standard curve corresponding to $f(\alpha)$ and $G(\alpha)$ were the most probable mechanism function [22] .

\section{Results and discussion}

\section{Thermal stability}

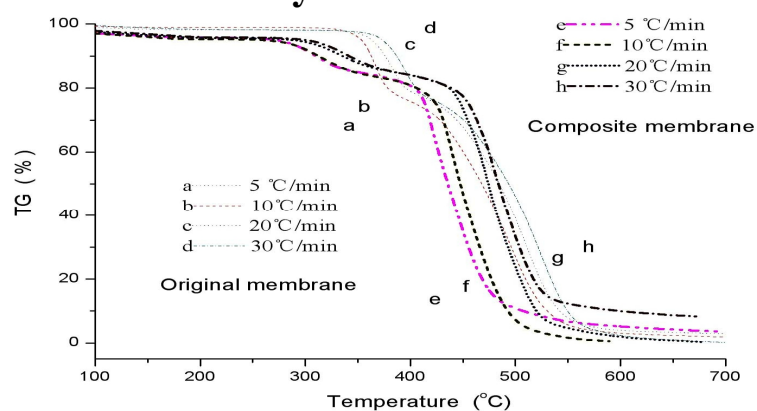

( a )

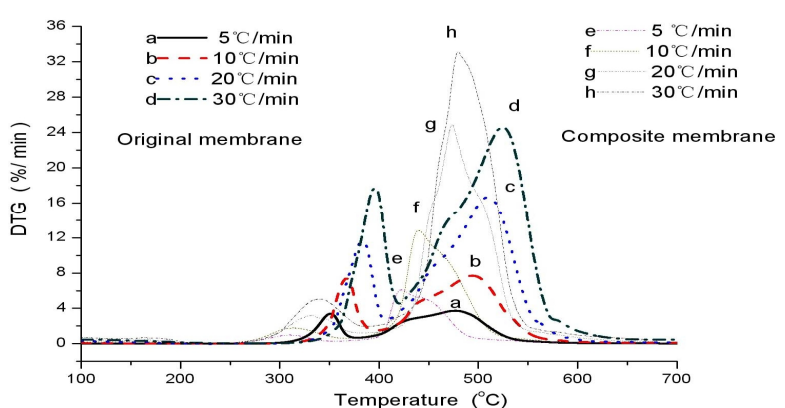

( b )

Fig. 1 TGA curves of composite membrane (a) - TG curves ; (b) - DTG curves

TG-DTG curves of composite film were shown in Fig.1, where a, b, c, d were corresponding to the thermal gravimetric curves of original film, e, $\mathrm{f}, \mathrm{g}, \mathrm{h}$ were corresponding to that of the silicotungstic acid doped composite film, heating rate was respectively 5,10, 20 and $30^{\circ} \mathrm{C} / \mathrm{min}$. In different heating rates, accompanying to increase of heating rate, TG curves offset to the high temperature zone in Fig. 1 
(a). The original film and the composite film can be divided into two thermal degradation phases, thermally decomposed interval of the original and composite film in first phase was at $310-420^{\circ}$ Cand $280-380^{\circ} \mathrm{C}$ and shown in Fig. 1(b). With respect to the temperature range of the second phase was at $420-600^{\circ} \mathrm{C}$ and $380-550^{\circ} \mathrm{C}$, comparing the peak temperature of composite film to that of original film, which offset to low temperature zone. Which may be due to silicotungstic acid containing a lot of water, with the temperature rise, the crystallization water was evaporated. In addition, the DTG curves were found that in the first phase at $300-400^{\circ} \mathrm{C}$, the thermal decomposition rate of the composite membrane significantly decreased, the peak temperature also decreased, indicating that the thermal stability of the composite film was improved. The second phase peak temperature also shifted slightly to the left side, at the range of $400-550^{\circ} \mathrm{C}$.

\section{Thermal decomposition kinetics}

When the heating rate was the $5,10,20$ and $30^{\circ} \mathrm{C} / \mathrm{min}$, the first phase of the peak temperatures respectively were $310.2,314.2,333.0$ and $340.1^{\circ} \mathrm{C}$, offset to the high temperature zone, corresponds to the second phase of the peak temperatures were $422.7,440.1,473.8$ and $479.6^{\circ} \mathrm{C}$, also moved to the high temperature zone. Plotting linearly relationship respectively curves for the $\lg \beta$ vs $1 / T_{p}, \ln \left(\beta / T^{1.8}\right)$ vs $1 / \mathrm{T}$ and $\ln (\mathrm{d} \alpha / \mathrm{dt})$ vs $1 / \mathrm{T}$, which were shown in Fig.2 (a), 2(b) and 2(c). Fig.3 shows the relationship curves of the composite film for the activation energy $\mathrm{E}$ and the decomposition rate of $\alpha$. When decomposition rate increases, the apparent activation energy $E$ was minor changed. The activation energies calculated by Friedman fluctuated significantly in $0.1-0.6$ intervals. The activation energy calculated by FWO method and Starink method at the interval of 0.2-0.9 are very close, but slightly less than activation energy calculated by FWO method, with Starink method. It can be inferred at $\alpha$ between 0.2-0.8, composite membrane for decomposition process was close.

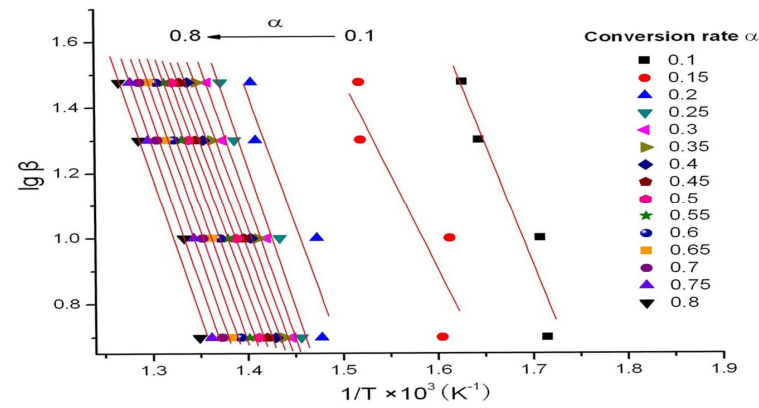

(a)

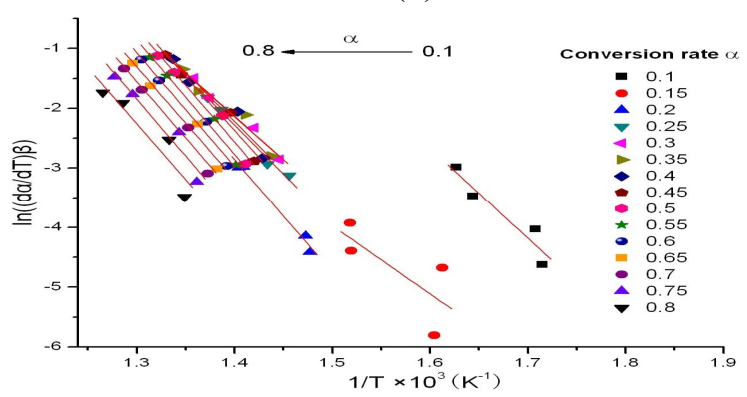

(c)

Fig. 2 Linear curves obtained by various methods

(a) $-\ln \beta$ vs $1 / \mathrm{T} ;$ (b) $-\ln \left(\beta / \mathrm{T}^{1.8}\right)$ vs $1 / \mathrm{T}$;

(c) $-\ln (\mathrm{d} \alpha / \mathrm{dt})$ vs $1 / \mathrm{T}$;

The kinetic parameters obtained were shown in Table 1 using FWO, Starink and Friedman methods for solving linear fit, the average activation energy E calculated by three different methods were $146.8,143.7$ and $143.1 \mathrm{~kJ} \cdot \mathrm{mol}^{-1}$, respectively. The activation energy calculated by FWO method is the biggest, the other two methods of activation energy is almost equal. 
Table 1 Thermal degradation kinetic parameters of composite membrane

\begin{tabular}{|c|c|c|c|c|c|c|c|c|c|}
\hline \multirow[t]{2}{*}{$\alpha$} & \multirow[b]{2}{*}{$\mathrm{E}\left(\mathrm{kJ} \cdot \mathrm{mol}^{-1}\right)$} & \multicolumn{3}{|c|}{ F-W-O } & \multicolumn{3}{|c|}{ Starink } & \multicolumn{2}{|c|}{ Friedman } \\
\hline & & r & SD & E & $\mathrm{r}$ & SD & E & $r$ & SD \\
\hline 0.10 & 133.5 & 0.9517 & 0.12875 & 131.4 & 0.9455 & 0.29649 & 125.7 & 0.9485 & 0.27505 \\
\hline 0.15 & 106.5 & 0.8870 & 0.19373 & 102.4 & 0.8691 & 0.44594 & 95.0 & 0.7443 & 0.65222 \\
\hline 0.20 & 147.1 & 0.9349 & 0.14893 & 144.3 & 0.9262 & 0.34296 & 157.5 & 0.9942 & 0.0995 \\
\hline 0.25 & 157.4 & 0.9889 & 0.06241 & 155.0 & 0.9873 & 0.14390 & 136.7 & 0.9933 & 0.09189 \\
\hline 0.30 & 153.2 & 0.9932 & 0.04899 & 150.4 & 0.9921 & 0.11300 & 121.2 & 0.9913 & 0.09605 \\
\hline 0.35 & 147.6 & 0.9925 & 0.05120 & 144.5 & 0.9914 & 0.11813 & 120.1 & 0.9730 & 0.17612 \\
\hline 0.40 & 144.9 & 0.9912 & 0.05546 & 141.6 & 0.9898 & 0.12793 & 135.9 & 0.9747 & 0.19571 \\
\hline 0.45 & 145.6 & 0.9893 & 0.06133 & 142.2 & 0.9875 & 0.14146 & 150.6 & 0.9794 & 0.19412 \\
\hline 0.50 & 147.2 & 0.9888 & 0.06267 & 143.8 & 0.9870 & 0.14455 & 157.7 & 0.9816 & 0.18942 \\
\hline 0.55 & 149.6 & 0.9884 & 0.06380 & 146.3 & 0.9865 & 0.14717 & 159.0 & 0.9839 & 0.17533 \\
\hline 0.60 & 151.8 & 0.9880 & 0.06494 & 148.5 & 0.9861 & 0.14979 & 158.6 & 0.9839 & 0.17251 \\
\hline 0.65 & 152.9 & 0.9867 & 0.06808 & 149.6 & 0.9847 & 0.15702 & 156.5 & 0.9794 & 0.19107 \\
\hline 0.70 & 154.2 & 0.9857 & 0.07065 & 150.9 & 0.9835 & 0.16295 & 156.8 & 0.9764 & 0.20353 \\
\hline 0.75 & 155.2 & 0.9837 & 0.07541 & 151.9 & 0.9812 & 0.17389 & 158.5 & 0.9657 & 0.24794 \\
\hline Average & 146.8 & & & 143.7 & & & 143.1 & & \\
\hline
\end{tabular}

Notes: $\alpha$-Conversion rate; E-Apparent Activation Energy; $\mathrm{r}$ - linear correlation coefficient; SD Standard deviation

Thermal degradation of composite membrane. Substituting the basic data obtained based on the TG-DTG curves of composite membrane, corresponding $f(\alpha)$ and $g(\alpha)$ into the formula (4) and (5), plotting the $\ln [\mathrm{d} \alpha / \mathrm{f}(\alpha) \mathrm{dT}]$ vs $1 / \mathrm{T}$ and $\ln \left[\mathrm{g}(\alpha) / \mathrm{T}^{2}\right]$ vs $1 / \mathrm{T}$ as linear fitting curve were shown in Fig.4(a)and (b) respectively. According to the linear relationship, as well as the standard deviation and the differential, integral method consistent results, the differential method (ABS method) and integration method (CR method) which calculated activation energies are 141.1 and $144.8 \mathrm{~kJ}^{-} \mathrm{mol}^{-1}$ is close to. The linear coefficient $r$ respectively was 0.9849 and 0.9997 , with a good correlation, standard deviation was 0.00789 and 0.00111 , and standard deviation is small. In the first phase, the composite film was found the decomposition mechanism function to be Mampel power rule, one-dimensional phase boundary reaction, $\mathrm{R} 1, \mathrm{n}=1$, power function law. In the second phase, decomposition mechanism of composite membrane was controlled by the two chemical reactions, F2. The activation energies calculated by the CR and ABS method were 141.2 and $143.4 \mathrm{~kJ} \cdot \mathrm{mol}-1$ is very close to. The linear coefficients were 0.9946 and 0.9999 , with a good correlation, standard deviations were 0.00956 and 0.00129 , and standard deviation is small.

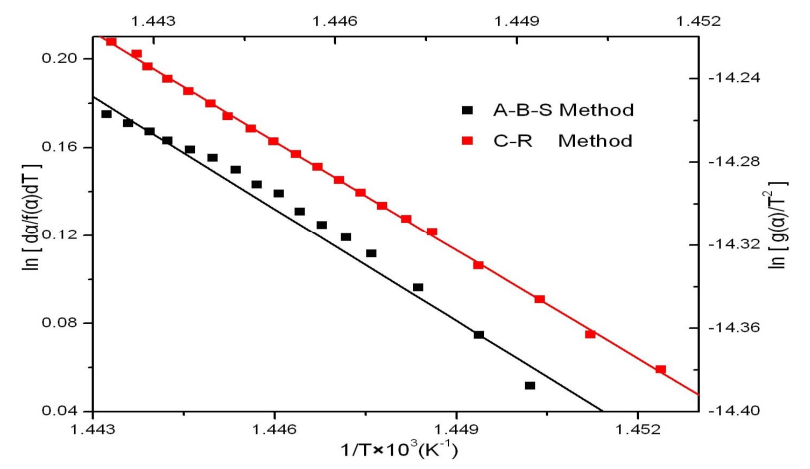

( a ) $1^{\text {st }}$ stage, $\beta=5^{\circ} \mathrm{C} / \mathrm{min}$

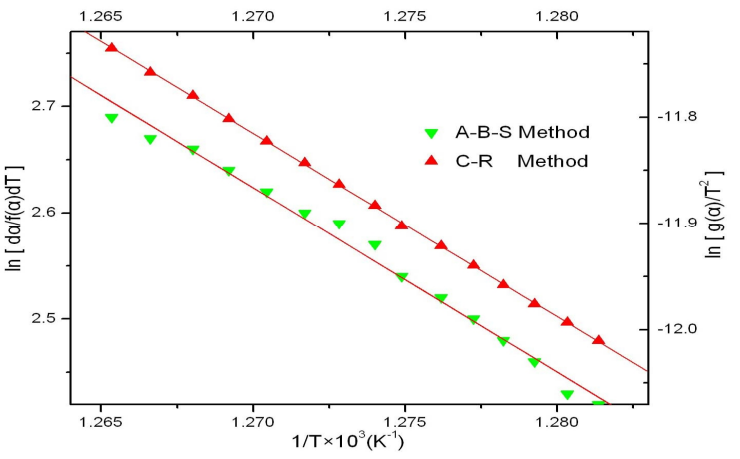

(b) $2^{\text {nd }}$ stage, $\beta=30^{\circ} \mathrm{C} / \mathrm{min}$

Fig. 4 Linear curves obtained by different stages $\ln [\mathrm{d} \alpha / \mathrm{f}(\alpha) \mathrm{dT}]$ vs $1 / \mathrm{T}$ by A-B-S method; $\ln \left[\mathrm{g}(\alpha) / \mathrm{T}^{2}\right]$ vs $1 / \mathrm{T}$ by C-R method

When heating rate was 5 and $30^{\circ} \mathrm{C} / \mathrm{min}$, according to formula (6) and (7), the $\mathrm{Z}(\alpha)-\alpha$ standard and test curves obtained were shown in Fig.5, where the curve 1 obtained was a standard curve, the curve 2 obtained was a experimental curve. When heating rate was $5^{\circ} \mathrm{C} / \mathrm{min}, \alpha$ was in the range of 0.29 to 0.32, the curve $Z(\alpha)$ vs $\alpha$ experimental and standard curve overlap and was shown in Fig.5 (a). 
Therefore, thermal degradation mechanism of composite film can be considered in the first phase as Mampel power rule. One-dimensional phase boundary reaction, $\mathrm{R} 1, \mathrm{n}=1$, a power law function, the differential equation $f(\alpha)=1$, the integral equation $G(\alpha)=\alpha$.

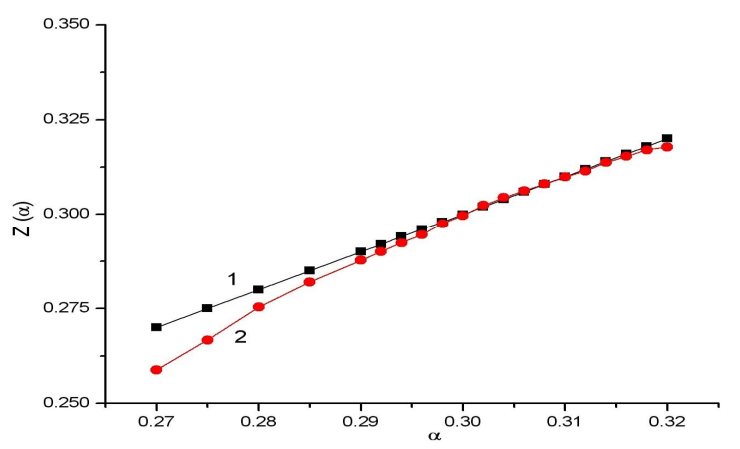

(a ) $1^{\text {st }}$ stage

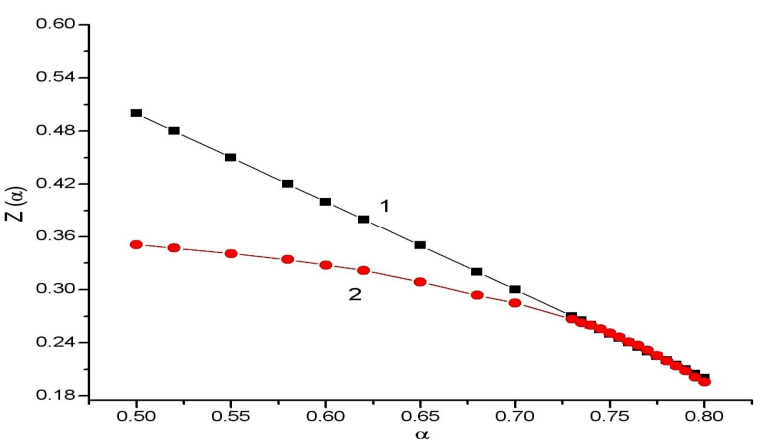

( b ) $2^{\text {nd }}$ stage

Fig. 5 Composite membrane curves of $Z(\alpha)$ vs $\alpha$

1- Standard curve; 2 - Experimental curve

When the heating rate was $30^{\circ} \mathrm{C} / \mathrm{min}, \alpha$ in the range of 0.72 to 0.8 , the curve $Z(\alpha)$ vs $\alpha$ experiment with a standard curves almost overlap and was shown in Fig.5 (b). Therefore, it can be considered that thermal degradation mechanism of composite film in the second phase was the secondary chemical reaction, F2. Mechanism functions for differential expression $f(\alpha)$ to be $(1-\alpha)^{2}$, integral expression $G$ $(\alpha)$ to be $(1-\alpha)^{-1}$.

\section{Impedance spectroscopy}

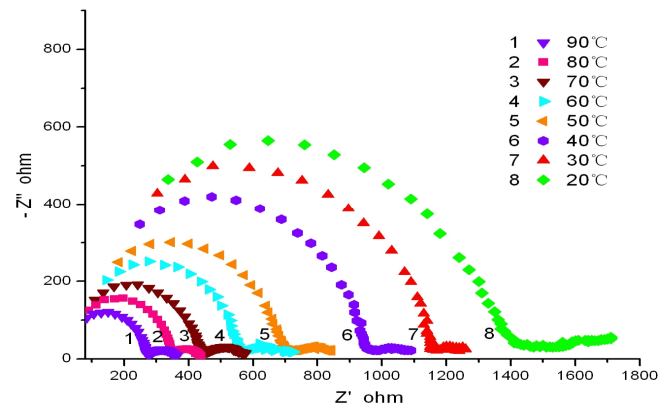

(a)

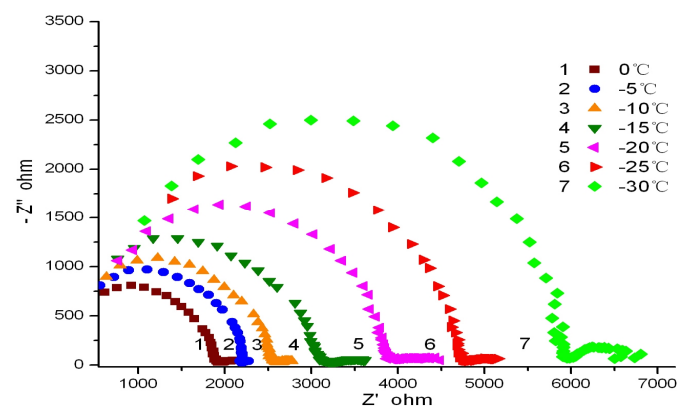

(b)

Fig. 6 Effect of temperature on the film impedance spectroscopy
(a) $20 \sim 90^{\circ} \mathrm{C}$;
(b) $-30 \sim 0{ }^{\circ} \mathrm{C}$

The effects of different temperature on impedance spectroscopy of original film and composite film were shown in Fig 6. At room temperature $\left(20^{\circ} \mathrm{C}\right)$, when the impedance value of composite film $Z^{\prime}$ is $1500 \Omega$, which is $42 \%$ of the original film resistance, indicating the silicotungstic acid doped proton exchange membrane had lower impedance value, when the temperature is $30-60^{\circ} \mathrm{C}, \mathrm{Z}^{\prime}$ is $1150-550 \Omega$, $Z^{\prime}$ changed greatly, but when the temperature rises above $70^{\circ} \mathrm{C}, Z$ 'is about $450-260 \Omega, Z$ ' had relatively small change, which is shown in Fig 6 (a).

When decreased at $-30^{\circ} \mathrm{C}$, and $Z^{\prime}$ is $6000 \Omega$ nearby, which is $56 \%$ impedance value of the original film, when $0^{\circ} \mathrm{C}$, the composite film $Z^{\prime}$ is about $1800 \Omega$, the original film resistance $30 \%$, showing that the decline in the low temperature range, the resistance value of the composite film were indicating that the conductivity increased and were shown in Fig 6 (b).

This suggests that when silicotungstic acid doped, improved the conductivity of the proton exchange membrane. As the temperature increased, the proton exchange composite membrane impedance varied not linearly, but gradually decreased, indicating a slow increase in the conductivity of the proton exchange membrane. 


\section{Conductivity}

Bulk resistance value $R_{b}$ of the film were taken the abscissa value of high-frequency and low-frequency line intersection semicircle corresponding impedance spectrum curves, if the test frequency is not too high or high conductivity system,

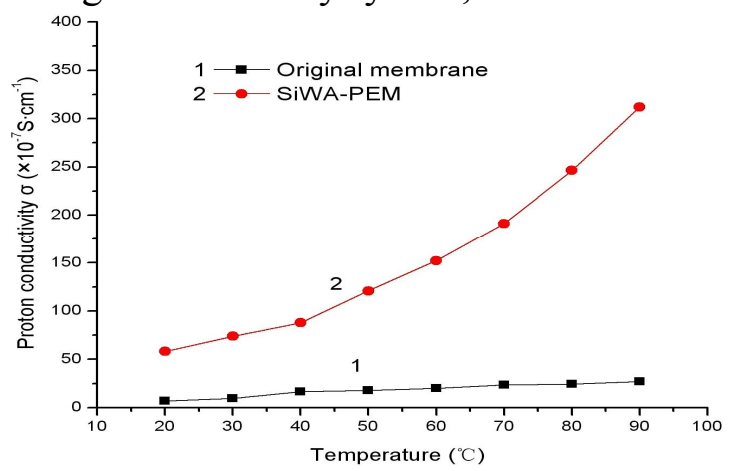

(a) $20-90^{\circ} \mathrm{C}$

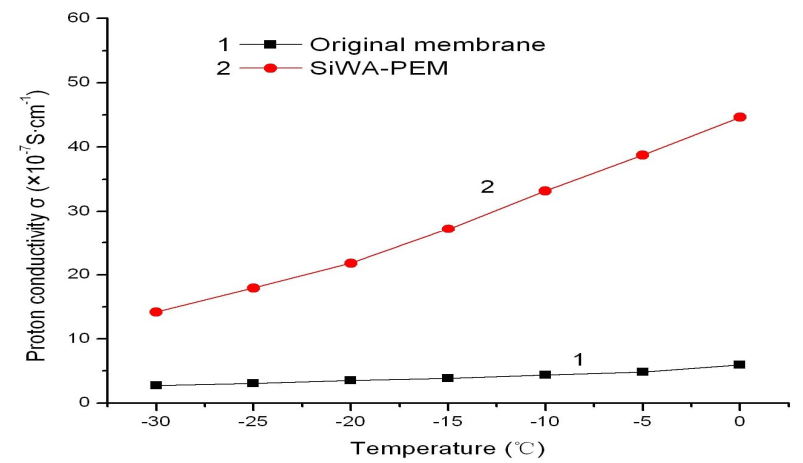

(b) $-30 \sim 0^{\circ} \mathrm{C}$

Fig. 7 Effect of temperature on conductivity of film

1- Original membrane; 2-Composite membrane

The high frequency semicircle does not appear, $R_{b}$ take the high-frequency end of the ionic conductivity of abscissa value when different temperatures are as follows:

8)

$$
\sigma=\mathrm{d} / \mathrm{R}_{\mathrm{b}} \cdot \mathrm{S}
$$

Where: $\sigma$ is the proton conductivity $\left(\mathrm{S} \bullet \mathrm{cm}^{-1}\right), \mathrm{d}$ is the thickness of the electrolyte membrane $(\mathrm{cm}), \mathrm{R}_{\mathrm{b}}$ is a volume resistivity $(\Omega)$ of the electrolyte membrane, $\mathrm{S}$ electrode and the electrolyte membrane contact area $\left(\mathrm{cm}^{2}\right)$, the proton conductivity of the film can be calculated according to the above formula, based on formula (8) to calculate the conductivity of the composite membrane, which were shown in Fig7. Wherein the composite membrane is $\mathrm{S} 1.76 \mathrm{~cm}^{2}, \mathrm{~d}$ is $150 \times 10^{-4} \mathrm{~cm}$, when heated at 20 90 ${ }^{\circ} \mathrm{Cand}-30 \sim 0^{\circ} \mathrm{Crange}$, conductivity changes curve with temperature were shown in Fig 7(a)(b). As can be seen from Fig7, when the temperature rose to $90^{\circ} \mathrm{C}$ from room temperature, the composite membrane conductivity was increased from $5.80 \times 10^{-6}$ to $3.12 \times 10^{-5} \mathrm{~S}^{\circ} \mathrm{cm}^{-1}$. When $-30^{\circ} \mathrm{Craised}$ to $0^{\circ} \mathrm{C}$, the conductivity increased from $1.42 \times 10^{-6}$ to $4.46 \times 10^{-6} \mathrm{~S} \cdot \mathrm{cm}^{-1}$. With rising temperatures, the proton conductivity of the film showed a slow increase trend. But at the low temperature as described above, below $0^{\circ} \mathrm{C}$, its conductivity increased at a rate significantly less than the above $0^{\circ} \mathrm{C}$. This is due to the increase in temperature help to improve the water content inside the film, and thermal motion of water molecules, making proton easier to pass through the proton exchange membrane to the cathode. Correspondingly, the thermal motion of water molecules becomes slow at low temperatures.

\section{Conclusions}

Thermal degradation of the composite film was divided into two phases, the peak temperature appeared at $310 \sim 350^{\circ} \mathrm{C}$ and $420 \sim 480^{\circ} \mathrm{C}$ in different heating rates, the peak temperature shifted to the left side, compared to original film. The average apparent activation energy calculated by the FWO, Starink and Friedman methods was $144.5 \mathrm{~kJ} \cdot \mathrm{mol}^{-1}$, along with decomposition rate increased tends to increase the apparent activation energy. Thermal degradation mechanism of the first phase of the composite film is Mampel Power law, one-dimensional phase boundary reaction, $\mathrm{R} 1, \mathrm{n}=1$, a power law function, $f(\alpha)$ is $1, G(\alpha)$ is $\alpha$. In the second phase, thermal degradation mechanism is the two chemical reaction, F2, deceleration $\alpha$-t-shaped curve, the mechanism of the function $f(\alpha)$ to be $(1-\alpha)^{2}$, $G(\alpha)$ to be $(1-\alpha)^{-1}$, with silicotungstic acid doped composite membrane, the decomposition characteristics was changed. When the temperature rose to $90^{\circ} \mathrm{Cfrom}$ room temperature, the composite membrane conductivity was increased from $5.80 \times 10^{-6}$ to $3.12 \times 10^{-5} \mathrm{~S}^{\circ} \mathrm{cm}^{-1}$. When 
$-30^{\circ}$ Cheated to $0^{\circ} \mathrm{C}$, the conductivity of composite membrane increased from $1.42 \times 10^{-6}$ to $4.46 \times 10^{-6}$ $\mathrm{S} \cdot \mathrm{cm}^{-1}$.

\section{Acknowledgements}

This research was financially supported by the following grants: (1) Anhui International Science and Technology Cooperation Program (06088018), (2) Huainan Municipal Science and Technology Program (2011A07923), (3) Anhui University of Science and Technology Graduate Education Fund (2014-2016).

\section{References}

[1] Hongwei Zhang, Pei Kang Shen, Recent development of polymer electrolyte membranes for fuel cells, Chem. Rev., 2012, 112: 2780-2832

[2] Deuk Ju Kim, Min Jae Jo, Sang Yong Nam, A review of polymer-nanocomposite electrolyte membranes for fuel cell application, Journal of Industrial and Engineering Chemistry, 2015 , 21:36-52

[3] M. Kourasia, R.G.A. Willsa, A.A. Shaha,b, F.C. Walsha, Heteropolyacids for fuel cell applications, Electrochimica Acta, 2014, 127: 454-466

[4] Kyu Ha Lee, Ji Young Chu, Ae Rhan Kim, Kee Suk Nahm, Cheol-Ju Kim, Dong Jin Yoo, Densely sulfonated block copolymer composite membranes containing phosphotungstic acid for fuel cell membranes, Journal of Membrane Science, 2013, 434: 35-43

[5] Jay Pandey, Fasil Qayoom Mir, Anupam Shukla, Performance of PVDF supported silica immobilized phosphotungstic acid membrane (Si-PWA/PVDF) in direct methanol fuel cell , International journal of hydrogen energy , 2014, 39:17306-17313

[6] Y1lser Devrim, Fabrication and Performance Evaluation of Hybrid Membrane based on a Sulfonated Polyphenyl Sulfone/Phosphotungstic acid/Silica for Proton Exchange Membrane Fuel Cell at Low Humidity Conditions, Electrochimica Acta, 2014, 146: 741-751

[7] Se-Hee Lee, Seong-Ho Choic, Sai-Anand Gopaland, Kwang-Pill Lee, Gopalan Anantha-Iyengare, Preparation of new self-humidifying composite membrane by incorporating graphene and

phosphotungstic acid into sulfonated poly(ether ether ketone) film International Journal of Hydrogen Energy, 2014, 39: 17162-17177

[8] Mehdi Amirinejad, Sayed Siavash Madaeni, Kwan-Soo Leeb, Un Kob, Ezzat Rafiee, Jae-Suk Lee,

Sulfonated poly(arylene ether)/heteropolyacids nanocomposite membranes for proton exchange membrane fuel cells, Electrochimica Acta, 2012, 62:227-233

[9] Mehdi Amirinejad, Sayed Siavash Madaeni, Ezzat Rafiee, Sedigheh Amirinejad, Cesium hydrogen salt of heteropolyacids/Nafion nanocomposite membranes for proton exchange membrane fuel cells, Journal of Membrane Science, 2011, 377 : 89- 98

[10] Uma Thanganathan, Masayuki Nogami, Synthesis of mixed composite membranes based polymer/HPA: Electrochemical performances on low temperature PEMFCs, Journal of Membrane Science, 2012, 411-412: 109- 116

[11] G. Lakshminarayana, Masayuki Nogami, Synthesis and characterization of proton conducting inorganic-organic hybrid nanocomposite membranes based on mixed PWA-PMA-TEOS-GPTMS-

$\mathrm{H}_{3} \mathrm{PO}_{4}$-APTES for $\mathrm{H}_{2} / \mathrm{O}_{2}$ fuel cells, J. Phys. Chem. C 2009, 113, 14540-14550 
[12] Michael B, McDonald, Michael S. Freund, Novel conducting polymer-heteropoly acid hybrid material for artificial photosynthetic membranes, ACS Appl. Mater. Interfaces, 2011, 3: 1003-1008

[13] Jie Zeng, San Ping Jiang, Characterization of high-temperature proton-exchange membranes based on phosphotungstic acid functionalized mesoporous silica nanocomposites for fuel cells, J. Phys. Chem. C 2011, 115: 11854-11863

[14] Yiheng Lu, Feng Wei, Yuwei Lv, Shuangchun Ma, Hanxu Li, Mingqiang Chen, Effect of Tungstophosphoric Acid Surface Treatment on the Thermal Stability of Proton Exchange Membrane for Fuel Cell, Polymer Materials Science \& Technology, 2014, 30(5):67-71

[15] Yiheng Lu, Wei Feng, Yuwei Lv, Weilong Liu, Hanxu Li,Mingqiang Chen, Effect of Pretreated Nano-Silica on the Thermal Stability of Proton Exchange Membrane, Polymer Materials Science \& Technology, 2013, 29(1):79-83

[16] Yi Heng LU, Feng Wei, Wei Long Liu, Effect of Fenton reagent on the thermal stability of proton-exchange membrane for fuel cell, Applied Mechanics and Materials, 2012, 217-219: 780-784

[17] Ozawa T. A new method of analyzing thermogravimetric data. Bull. Chem. Soc. Jpn., 1965, 38(11): $1881-1886$

[18] Friedman H L.Kinetics of thermal degradation of char-forming plastics from thermogravimetry Application to phenolic plastic. J. Polym.Sci.Part C: Polyn.Symp. 1964, 6: 183-195

[19] Starink M J. A new method for the derivation of activation energies from experiments performed at constant heating rate. Thermochimica Acta, 1996, 288(1-2): 97-104

[20] ACHAR B N, BRIDLEY G W, SHARP J H. Thermal decomposition kinetics of some new unsaturated

polyesters. Proc Int Clay Conf, 1966, 1: 65-72

[21] COATS A W, REDFERN J P. Kinetic parameters from thermogravimetric data. Nature, 1964, 201(4914): 68-69

[22] R. Z.Hu, Q. Z. Shi, The thermal analysis kinetics, second edition. Beijing: Science Press, 2008:151-155 